\title{
Research on Teaching Reform of SCM Course under the Goal of Training Excellent Engineer
}

\author{
Cuimei Li ${ }^{1, a}$, Ming Yang ${ }^{2, b}$ and Le Huang ${ }^{3, c}$ \\ ${ }^{1}$ School of Communication and Electronic, Jiangxi Science \& Technology Normal University, \\ Nanchang, 330013, China \\ ${ }^{2}$ Sub- Bureau of Quality and Technology Supervision, Nanchang Qingshan Lake District , \\ Nanchang, 330013, China \\ ${ }^{3}$ School of Computer Grade 12, Central China Normal University, Wuhan 430079, China \\ a996506207@qq.com, b120066722@qq.com, ${ }^{\text {'5 } 505103350 @ q q . c o m ~}$
}

Keywords: SCM; Excellent engineers; Theory teaching method; Experiment teaching method; Reform

\begin{abstract}
The SCM course teaching has the characters of rich contents, diversified forms, and close relation to reality. Aiming at the practical problems existing in the course teaching, this paper puts forward a concrete teaching reform method under the goal of excellent engineer training introduction. Through the establishment of a complete knowledge system of the courses and practice system, this article points out the aim of teaching reform, which is just to raise the students' ability of practicing the project, designing innovatively, and boost their spirit of team work. The teaching method proposed in this paper is suitable for the teaching practice of single chip microcomputer professional course.
\end{abstract}

\section{Introduction}

Nowadays, many domestic universities have introduced the teaching reform of the SCM(single-chip computer) course continuously, and proposed the suggestions of the mutual complementation between the introducing EDA simulation and hardware experimental teaching, and of using web-based learning platform to expand the teaching time and space, and introducing the multimedia teaching[1]. These research results have some for reference, but the social need is those who have strong practical ability of engineering, excellent engineering talents, virtual experiment and network teaching isn't actually do good to cultivation of practical ability, only as a supplement; many universities and colleges abroad have also carried on the reform of the engineering education link and they have created the personal training mode, course system, teaching methods of adapting to social demands, and have paid attention to the training of application, practice and innovative[2], however, at home and abroad currently, it's rarely able to find the data which is regard excellent engineers as training objectives. The reform of this course to carry out is to cultivate and improve the two important capacities --the innovative thinking and ability of practicing the project, in order to cultivate research-oriented researchers and design engineers. The teaching reform aims at the specific characteristics and the practical problems existing for "single-chip computer application technology" course, regarding cultivating innovative and top-notch excellent engineers as training objectives, to study and reform of this course. SCM course has the following problems: teaching materials lagged behind, in the past, the teaching materials are compiled mostly at the base of traditional 8051 SCM[3], and the course's teaching arrangement is in accordance with the teaching materials content, but the development of single-chip technology change rapidly, how to solve the contradiction between the rapid development of SCM technology and old teaching materials, it is the key problem need to be solved in the reform of SCM teaching; the teaching method is old, the traditional teaching mode is mainly teaching, the students listen to the teacher carefully in class, and do certain hours experiment outside class, this teaching mode makes the poor interaction between teachers and students, it is difficult to inspire students' interest in learning; assessment of single 
mode, The traditional examination mode is close examination in the final exam, this will cause the passive memory of students, it is difficult to mobilize the enthusiasm of the students, Reasonable reform of examination mode is Imminent.

\section{The theory teaching reform of " SCM Application Technology " Course}

The adjustment of course content. The traditional SCM has single function, low processing speed, little memory space, thus it need to use three bus (data bus, the address bus and control bus) architecture of SCM to expanse its function. With the development of semiconductor technology, the single chip which is integrated more functional modules in the same package even smaller package have unparalleled processing speed and storage capacity, causing the gradual reducing of the application based on three bus architecture for parallel extension, so at the class, the teachers only teach parallel extensions briefly to the extent of understanding what it is, and the introduction of the serial expansion based on SPI bus, I2C bus can be increased at the same time [4]. In addition, because the modern SCM improves the processing speed, increases storage space and promotes The performance of the compiler development environment, Assemble language in the development of $\mathrm{SCM}$ is no longer a dominant position. A large amount of SCM procedures based on C language take the place of it. So only in Teaching, students understand the assemble language of the advantages and disadvantages, familiar with basic instruction format, can carry on the general Simple programming, can also grasp the method of hybrid programming with $\mathrm{C}$ language compilation. In the single chip microcomputer programming language teaching, the teacher should focuses on similarities and differences of the embedded $\mathrm{C}$ language and based on PC C language. In addition, some chips having no practical value, such as D/A chip -DAC0832, A/D chip -AD0809, needn't to be introduced in the classroom teaching, and some commonly used external interface chips should be introduced, such as DS18B20 temperature sensor based on 1-wire bus, AlD, D/A, keyboard control, display control and memory chips based on extending serial interface".

The reform of the teaching methods. The common traditional teaching way is the spoon-feeding teaching, and the way is teaching-oriented teaching model, students just listen to the teachers and take notes. This way cannot fully motivate the enthusiasm of the students' learning, and also cannot help students' innovative thinking. Modern teaching advocates "research" teaching, with the more interaction in the process of teaching, which actively guide students to dig deeply to the content, emphasis on students' independent learning ability, and cultivate students' scientific research ability, but can not completely deny the traditional teaching model. Traditional teaching model attains much importance to the basic knowledge, which can make students lay a solid foundation of understanding of courses, so teachers should combine research teaching model with traditional one reasonably when teachers teach Single-chip Principle and Application, which not only focus on basic knowledge, but also guide the students to actively thinking and diligent practice[5]. This avoids the drawback of high scores and low abilities, but also help students to lay a solid theoretical basis for engineering practice.

The change of assessment methods. Change the closed-book examination into the open-book one, and increase the setting the open question, test students deeply on the flexible application of knowledge rather than the memory ability of it; introduce multiple evaluation system to avoid the limitation of single evaluation standard of students. After the reform of the course examination combined with the three kinds of three examination which are open-book examination, experimental examination and open self-selecting examination. The reason why we should change the closed-book examination into the open-book examination is that "SCM Application Technology " course is more applicative than theoretical, and it focuses on the command of the tool SCM and the degree of its application to practice rather than the memory of the knowledges. It's more effectively to find out whether the students have a good flexible command of knowledge under the open-book examination. At the same time, with the aid of experimental examination, it can strengthen the students' practical ability. Finally, teachers give some open self-selecting assignments to let the students choose the content they interested in for in-depth studying, the open homework is mostly let students use the Proteus simulation software to realize some little functions. The use of simulation software to let the 
students no longer limited to the limited experimental class and experimental equipment, which is aiming at making it more multifaceted, flexible, in-depth to learn SCM knowledge.

\section{The practical teaching reform of " SCM Application Technology" Course}

The rational allocation of the experiment content. As for the most of students, the procedure of experiment is the important link that they should change classroom knowledge into practical ability. On the basis of guarantee experimental learning period, by improving the scale of comprehensive design experiments in the experimental procedure, to cultivate students' comprehensive abilities in problem solving, and by the training of certain basic experiments, students can be quickly familiar with the development process and the basic structure of SCM. In addition, teachers can hand out the experiment guide book in advance to the students, let them build a hardware system through Proteus simulation software in advance on their computer experiment from the guide book, program according to the instructions, and finally carry on the simulation debugging. After debugging accepted, it can be used in real hardware platform of laboratory for verification. On one hand students can master the simulation software, on the other hand it can save large amount of time to arrange experiments, in order to arrange more experimental contents within the limited experimental period and let the students to understand the SCM more deeply.

Promoting scientific research results into the classroom. As an very applicative and practical course, "Single-chip Microcomputer Application Technology" needs teachers full of rich experience in engineering, and they can introduce these experience and research results into the "Single-chip Microcomputer Application Technology " class. On one hand, this can improve students' learning interest; on the other hand, it can make the students know where, why, how to use the SCM, and how to use it better[6]. At the same time, teachers can regard single-chip microcomputer as the core when teaching, guide students to develop preliminary project consciousness, to grasp the preliminary project research and engineering innovation method.

Introduction of the latest technology. At present, more and more the companies will hold some product seminar every fixed time. In the seminar every company will combine with its company's SCM products to introduce some actual industrial use cases, and the new SCM development direction and the latest SCM product will be also introduced at the same time. Therefore, teachers can collect the information of some SCM related seminars, and pick out the appropriate one to encourage students to participate in according to teaching schedule and the level of students' command of SCM. Judging from the feedback situation, the students have a very strong interest in participating in this kind of seminar, they can not only learn the specific application of SCM, but deepen their understanding of the SCM use in the industry situation by communicating with design engineers at the meeting, which can contributes to their more interest and motivation in learning SCM in the classroom, and thus form a positive cycle.

Encouraging participation in science and technology competition. At present, a lot of countries and the various colleges and universities each have held some students science and technology competitions[7], and the competitions are expected to motivate the enthusiasm of students, and contribute to the realization of the transformation from the theory study into the practice ability. SCM, as a universal microcontroller can be used in the industry, agriculture, aerospace, military and other industries, is very suitable for students to participate in science and technology competition[8]. In teaching, teachers should guide and encourage the students to play the creative thinking of their own, and combine with knowledge they have learned to participate actively in the relevant scientific and technological competition, and at last, they can achieve the goal that put their knowledges and skills into full use and the enough exercise and experience of it[9].

\section{The effect of the teaching reform}

After Taking the above measures and two years' teaching practice, students generally have more interest in"single-chip computer application technology" learning than before, and grasp and apply the knowledge better, at the same time, by the amounts of practical teaching procedures, it's very 
easy for students to transform the classroom knowledge into practice. In addition, there are students participating in the national electronic design contest, robot contest, the SRTP project, the "Feng Ru Cup" science and technology competition by using of the single-chip computer knowledge, and they has obtained medals and achievements in the competition.

\section{Conclusions}

With the rapid development of the single-chip computer technology, the teaching reform of the "single-chip computer application technology" course also be imperative. Aiming at the problem of "single-chip computer application technology" teaching, combined with the position of the research university, and regarding excellent engineers cultivation as objectives I elaborate the content of the teaching reform of the "single-chip computer application technology" course in detail. The specific reform methods have strengthened the cultivation of the students' creative thinking ability and the practical ability training successfully. The teaching and research work has withstood the test of practice, won the unanimous approval of the relevant teachers and students.

\section{Acknowledgements}

This work was supported by the Provincial Project of Teaching Reform and Research of Colleges and Universities in Jiangxi Province(Grant No. JXJG-13-10-15), the Key Project of the Educational Science Twelve-Five Year Plan of Jiangxi Province (Grant No. 13ZD3L038) and the Scientific and Technological Program of Jiangxi Provincial Education Development (Grant No. GJJ14583).

\section{References}

[1] Syed R. Rizvi. Microcontroller Programming: An Introduction[M]. CRC Press, 2011:1-50.

[2] Dogan Ibrahim. Microcontroller Based Applied Digital Control[M]. Wiley, 2006:25-35.

[3] Yigang zhang. Xiyuan Peng. Yu peng Single-chip microcomputer principle and application [M]. Second edition. Beijing: higher education press, 2010:1-27. (In Chinese)

[4] Deyun Xiao. etc. To create research teaching system of automation, cultivating innovative professional talent of [J]. Journal of electrical and electronics teaching, 2009, (S2):91-100. (In Chinese)

[5] Tengfei zhang, Yiran Gu, Jing Wang. Embedded electrical engineering practice teaching content and method reform exploration [J]. Electric power education in China, 2009, (7):156-158. (In Chinese)

[6] Bo Yang, Beiyang. Use professional foundation courses to strengthen the cultivation of college students' innovative quality [J]. Journal of Beijing university of aeronautics and astronautics (social science edition), 2011, 24 (2):109-112 (In Chinese)

[7] WangWei. Teaching thinking of the about the professorship automation of embedded technology in the ordinary university [J]. Electrical and electronic teaching journal, 2010, 32 (3):9-13. (In Chinese)

[8] J. Shao. The SCM experiment teaching using the action orientation teaching method[C]. Proc. The vocational education educational reform (Shanghai, China, November 16, 2009), p.327-330. (In Chinese)

[9] J. Lu and X.L Kang. The teaching practical and explore of the SCM course[C]. Proc. The Wuxi vocational education educational reform (Wuxi, China, November 1, 2009), p.178-180. (In Chinese) 